\title{
MONOSEMICARBAZONE OF ADRENOCHROME (ADRENOXYL) AND CATARACT SURGERY* EFFECT ON CAPILLARY RESISTANCE AND INCIDENCE OF HYPHAEMA
}

BY

\author{
H. T. SWAN, A. B. NUTT, G. H. JOWETT, $\dagger$ \\ W. J. WELLWOOD FERGUSON, AND E. K. BLACKBURN \\ From the Departments of Haematology and Ophthalmology, Royal Infirmary, Sheffield, and \\ the Department of Statistics, University of Sheffield
}

EPINEPHRINE, from which the monosemicarbazone of adrenochrome is derived, has a powerful action on arterioles and capillaries. It causes the small muscles of the micro-circulation to contract and this lessens the flow of blood within the vessels. The part thus played by endogenous epinephrine in helping to control the physiological flow of blood is more clearly defined than any supposed function it has in stopping blood loss. When there is bleeding from capillary damage, pharmaceutical epinephrine can be used as a haemostatic for local application, but epinephrine would be of greater value in capillary bleeding if its effect were more lasting. When given systemically, it has not proved of any value in reducing blood loss, and may, indeed, aggravate this by its known action on the mechanism for dissolving away formed clots (Biggs, Macfarlane, and Pilling, 1947).

Epinephrine itself is a very active chemical, but is readily oxidized to adrenochrome. This was first isolated by Green and Richter (1937). Adrenochrome was shown by Roskam and Derouaux (1944) to produce capillary haemostasis as did epinephrine, and like it was also unstable. In view of its instability, Braconier, Le Bihan, and Beaudet (1943) elaborated the monosemicarbazone of adrenochrome (Adrenoxyl) which is said to be stable and to possess haemostatic properties when given by mouth or by injection.

Many claims have been made for Adrenoxyl. It is said that the drug increases capillary resistance in the sub-clavicular region in man and the lumbar region in the guinea-pig (Prévost, Cotereau, and Parrot, 1947). It is also reputed to increase cardiac output with no effect on the blood pressure or pulse rate (Hervé, 1951) and to stimulate the adrenal cortex slightly (van Cauwenberge, Lecomte, Fischer, Vliers, and Goblet, 1953). So far as can be ascertained from the literature it has never produced toxic or allergic side-effects and does not affect blood coagulation, nor does it

* Received for publication August 12, 1960.

† Present address: Department of Statistics, University of Melbourne, Australia. 
accumulate in the reticulo-endothelial system. Adrenoxyl may be given by mouth or parenterally.

Delayed hyphaema is a well-known and troublesome complication of operations for cataract and sometimes causes cicatrization and functional disorders of the eye. We decided therefore to attempt an assessment of the value of Adrenoxyl in cataract surgery by observing such changes as it might produce in skin capillaries, as shown by their resistance to negative pressure. Concurrently the development of hyphaema was looked for and its relationship to Adrenoxyl therapy and capillary resistance was established.

Because of the results obtained, the trial was then extended on more clinical lines to find out whether Adrenoxyl has a significant influence on the incidence of hyphaema following cataract surgery.

\section{Part I. Effect of Adrenoxyl on Capillary Resistance to Negative PRESSURE}

\section{Methods}

Choice of Patient and Dosage of Adrenoxyl.-The design of the first part of the trial was based on a preliminary sampling of some unsystematic records of capillary pressure which were available. These suggested that:

(a) the operation might itself have an effect on capillary resistance,

(b) between-patient variability was so large as to make it desirable to use each patient as control for himself, i.e. to take observations of capillary pressure on the same patient when under treatment with Adrenoxyl and when not under treatment.

In addition these records gave an indication of the size of trial necessary.

Sixteen patients admitted for lens extraction were investigated in the main trial. Twelve of these were non-diabetic (Cases A1 to A6, B1 to B6) and four were diabetics (Cases A7, A8, B7, and B8). Within these two groups the patients were paired according to sex but were otherwise taken in strict sequence on their random admission to hospital. The first of each pair of patients to be admitted for operation was allocated to the letter A or B by the tossing of a coin.

The patients in Group A received four tablets $(10 \mathrm{mg}$.) Adrenoxyl every 8 hours for 4 days, 2 days being before the lens extraction, the third being the day of operation, and the fourth being the first post-operative day. During the succeeding 4 days Adrenoxyl was withheld. The drug was then taken in the former dosage for a further 4 days, and stopped for the last 4 days.

The patients allocated to Group B received no Adrenoxyl on the 2 days before operation, the day of operation, and the day following. During the succeeding 4 days they received four tablets Adrenoxyl every 8 hours, in 
the next 4 days they received none, and for the last 4 days they received the drug again in the same dosage. This schedule was what may be called the mirror image of Schedule A.

The two equal groups of patients were given different schedules of Adrenoxyl therapy to enable the effect of the operation, if it existed, to be eliminated in analysis simply by averaging over both groups, a positive effect on differences in one group cancelling a corresponding negative effect in the other group.

Operation.-The lens extractions were performed by surgeons who were members of two surgical teams. The premedication, local anaesthetic, and nursing were the same in each pair of cases A and B.

Estimation of Capillary Resistance.-This was done by the negative pressure method advocated by Scarborough (1941), using an apparatus similar and comparable to his own, but modified to incorporate an aneroid manometer. The cup of the apparatus had an internal diameter of $20 \mathrm{~mm}$. and was applied in turn, for exactly 30 seconds, to each of three areas on the left arm of the patient. The three areas chosen were on the volar aspect of the forearm as used by Scarborough (1941) and Robson and Duthie (1950). The figure sought was the negative pressure at which only one capillary ruptured ("critical pressure"). If no petechiae were produced, the negative pressure was increased by stages of $50 \mathrm{~mm}$. until more than one petechia appeared. When more than one petechia was produced at a time, it was assumed, for the purposes of charting, that the number of petechiae appearing was proportional to the increase above the critical pressure, provided this remained within the limits of the $50 \mathrm{~mm}$. increase, and an arbitrary figure of five was subtracted from the manometer reading for each petechia after the first. An average was made of the "critical pressures" of the three areas for each day. The same three areas were tested on each occasion by the same observer at the same time on each of the 16 days. It was not known at the time of the examination whether the patient was receiving Adrenoxyl or not.

Post-operative Complications.-Eye dressings were removed once a day and any post-operative haemorrhage in the eye was noted at that time.

\section{Results}

Statistical Analysis of the Pressure at which Capillaries began to Rupture.The data were analysed logarithmically, since there appeared to be marked differences in level of capillary resistance from patient to patient, variation increasing with level, and ratios were considered to be a more appropriate measure of comparison than absolute differences of capillary resistance (Table I). The logarithm of the average capillary resistance for the three 
positions (left medial elbow, left lateral elbow, left wrist) was calculated for each patient on each day, except in the case of Patient A7, whose skin was ichthyotic, making reasonable estimations impossible except over the left lateral elbow position, where the skin was relatively normal. This substitution was a reasonable one, and can be safely assumed not to have affected the validity of the analysis.

TABLE I

SUMMARY OF LOGARITHMIC AVERAGES

\begin{tabular}{|c|c|c|c|c|c|c|c|}
\hline \multicolumn{2}{|c|}{ Patient No. } & \multicolumn{2}{|c|}{$\begin{array}{l}\text { Mean log. Critical } \\
\text { Capillary Resistance } \\
\text { (Value in mm. Hg } \\
\text { in brackets) }\end{array}$} & \multicolumn{2}{|c|}{$\begin{array}{l}\text { Mean log. Critical } \\
\text { Resistance (with } \\
\text { Adrenoxyl) minus } \\
\text { Mean log. Critical } \\
\text { Resistance (without } \\
\text { Adrenoxyl) } \\
\text { (Arithmetic Ratio } \\
\text { in brackets) }\end{array}$} & \multicolumn{2}{|c|}{$\begin{array}{l}\text { Mean log. Critical } \\
\text { Resistance (post- } \\
\text { operative) minus } \\
\text { Mean log. Critical } \\
\text { Resistance (pre- } \\
\text { operative and day of } \\
\text { operation) } \\
\text { (Arithmetic Ratio } \\
\text { in brackets) }\end{array}$} \\
\hline Group A & $\begin{array}{l}\text { A1 } \\
\text { A2 } \\
\text { A3 } \\
\text { A4 } \\
\text { A5 } \\
\text { A6 (diabetic, } \\
\text { A7 (dia only) } \\
\text { LLE on (diabetic) }\end{array}$ & $\begin{array}{l}2 \cdot 274 \\
2 \cdot 427 \\
2 \cdot 302 \\
2 \cdot 392 \\
2 \cdot 238 \\
2 \cdot 430 \\
\\
2 \cdot 227 \\
2 \cdot 292\end{array}$ & $\begin{array}{l}(188) \\
(267) \\
(200) \\
(247) \\
(173) \\
(269) \\
\\
(169) \\
(196)\end{array}$ & $\begin{array}{l}-0.035 \\
-0.095 \\
-0.003 \\
+0.004 \\
-0.011 \\
+0.035 \\
-0.051 \\
-0.055\end{array}$ & $\begin{array}{l}(0.92) \\
(0.80) \\
(0.99) \\
(1.01) \\
(0.98) \\
(1.08) \\
\\
(0.89) \\
(0.88)\end{array}$ & $\begin{array}{l}+0.126 \\
+0.107 \\
+0.051 \\
-0.096 \\
+0.012 \\
-0.092 \\
+0.013 \\
+0.009\end{array}$ & $\begin{array}{l}(1 \cdot 34) \\
(1 \cdot 28) \\
(1 \cdot 13) \\
(0 \cdot 80) \\
(1 \cdot 03) \\
(0 \cdot 81) \\
\\
(1 \cdot 03) \\
(1 \cdot 02)\end{array}$ \\
\hline \multicolumn{2}{|c|}{$\begin{array}{l}\text { Mean for Patients in A } \\
\text { Group }\end{array}$} & $2 \cdot 323$ & (210) & -0.026 & $(0.94)$ & +0.016 & $(1.04)$ \\
\hline Group B & $\begin{array}{l}\text { B1 } \\
\text { B2 } \\
\text { B3 } \\
\text { B4 } \\
\text { B5 } \\
\text { B6 } \\
\text { B7 (diabetic) } \\
\text { B8 }\end{array}$ & $\begin{array}{l}2 \cdot 306 \\
2 \cdot 254 \\
2 \cdot 297 \\
2 \cdot 192 \\
2 \cdot 534 \\
2 \cdot 303 \\
2 \cdot 467 \\
2 \cdot 324\end{array}$ & $\begin{array}{l}(202) \\
(180) \\
(198) \\
(156) \\
(342) \\
(201) \\
(293) \\
(211)\end{array}$ & $\begin{array}{l}+0.061 \\
+0.005 \\
+0.011 \\
+0.031 \\
+0.018 \\
-0.071 \\
+0.098 \\
+0.089\end{array}$ & $\begin{array}{l}(1.15) \\
(1.01) \\
(1.03) \\
(1.07) \\
(1.04) \\
(0.85) \\
(1.25) \\
(1.23) \\
\end{array}$ & $\begin{array}{l}+0.180 \\
-0.009 \\
+0.043 \\
+0.161 \\
+0.046 \\
-0.208 \\
+0.114 \\
+0.074\end{array}$ & $\begin{array}{l}(1 \cdot 51) \\
(0.98) \\
(1 \cdot 10) \\
(1.45) \\
(1 \cdot 11) \\
(0.62) \\
(1 \cdot 30) \\
(1 \cdot 19)\end{array}$ \\
\hline \multicolumn{2}{|c|}{$\begin{array}{l}\text { Mean for Patients in B } \\
\text { Group }\end{array}$} & $2 \cdot 335$ & (216) & 0.030 & $(1 \cdot 07)$ & +0.050 & $(1 \cdot 12)$ \\
\hline \multicolumn{2}{|c|}{$\begin{array}{l}\text { Mean for All Patients in } \\
\text { Trial }\end{array}$} & $2 \cdot 329$ & (213) & 0.002 & $(1 \cdot 01)$ & +0.035 & $(1 \cdot 08)$ \\
\hline 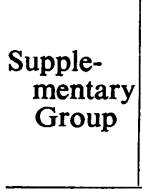 & $\begin{array}{l}\text { S1 (diabetic) } \\
\text { S2 (diabetic) } \\
\text { S3 } \\
\text { S4 } \\
\text { S5 } \\
\text { S6 }\end{array}$ & $\begin{array}{l}2 \cdot 031 \\
2 \cdot 286 \\
2 \cdot 397 \\
1.940 \\
2 \cdot 259 \\
2 \cdot 231\end{array}$ & $\begin{array}{r}(107) \\
(193) \\
(250) \\
(87) \\
(182) \\
(230)\end{array}$ & \multirow{3}{*}{\multicolumn{2}{|c|}{ Not Applicable }} & $\begin{array}{l}-0.139 \\
+0.020 \\
+0.018 \\
+0.052 \\
+0.013 \\
-0.034\end{array}$ & $\begin{array}{l}(0.73) \\
(1.05) \\
(1.04) \\
(1.13) \\
(1.03) \\
(0.92)\end{array}$ \\
\hline \multicolumn{2}{|c|}{$\begin{array}{l}\text { Mean for Supplementary } \\
\text { Patients }\end{array}$} & $2 \cdot 212$ & (163) & & & -0.012 & $(0 \cdot 97)$ \\
\hline \multicolumn{2}{|c|}{ Mean for All Patients } & $2 \cdot 297$ & (198) & & & 0.021 & $(1 \cdot 05)$ \\
\hline
\end{tabular}


The average log. capillary resistance (C.R.) for Adrenoxyl periods, was compared with the average log. C.R. for non-Adrenoxyl periods, and was found not to differ significantly. The apparent effect of Adrenoxyl was thus virtually nil. From the size of the variation it can be asserted that, even if the trial has turned out negative by chance, any real effect is very likely (95 per cent. probability) to be less than 6.5 per cent. The difference between average log. C.R. for Adrenoxyl and non-Adrenoxyl periods was significantly (5 per cent. level) less in the A group than in the B group and this different response to the $A$ and to the $B$ dosage pattern must be ascribed to the effect of the operation on capillary resistance. These results are summarized in Table I and the analysis of variance test of significance in Table II.

\section{TABLE II}

ANALYSIS OF VARIANCE FOR AVERAGE LOG. CRITICAL CAPILLARY RESISTANCE (ADRENOXYL) MINUS AVERAGE LOG. CRITICAL CAPILLARY RESISTANCE (NON-ADRENOXYL)

\begin{tabular}{l|c|c|c}
\hline Mean Effect of Adrenoxyl & $\begin{array}{c}\text { Sum of Squares } \\
60 \cdot 1\end{array}$ & $\begin{array}{c}\text { Degrees of } \\
\text { Freedom } \\
1\end{array}$ & $\begin{array}{c}\text { Mean Square } \\
60 \cdot 1 \text { (N.S.) }\end{array}$ \\
\hline $\begin{array}{l}\text { Difference between Means of A and } \\
\text { B Groups due to Effect of Opera- } \\
\text { tion }\end{array}$ & 12,826 & 1 & $\begin{array}{c}12,826 \\
\text { (Significant at } \\
5 \text { per cent. level) }\end{array}$ \\
\hline Difference within Groups & 32,079 & 14 & 2,291 \\
\hline
\end{tabular}

$($ Unit $=0.001)$

Significantly more ( 5 per cent. level) cases show a rise in average log. C.R. after the operation than show a fall (twelve rises compared with four falls), though in patients where there was a fall it was occasionally very marked (e.g. in Patient B6 who did not develop hyphaema). It was justifiable to lump the A and B patients together for this comparison in view of the lack of effect of the drug.

Six cases were available from a previous trial using $5 \mathrm{mg}$. ( 2 tabs) 8-hrly of Adrenoxyl. It was believed that these could fairly be included with the 16 trial cases to assess the effect of the operation. In these six cases, the records of the capillary resistance for the pre-operative and operative days were available, but occasional observations were missing for the thirteen post-operative days. The results for this supplementary group are given in the lower section of Table I. While the mean log. C.R. is lower than in the major trial and the average is, if anything, slightly less, the capillary resistance rose in four cases after operation compared with two which fell, confirming the significance of the comparison above. 
Post-operative Hyphaema.-This occurred in six of the sixteen patients. Only one patient of the six (A5) developed hyphaema while receiving Adrenoxyl and without any obvious precipitating cause. Two of these six (B1 and B5) had been taking Adrenoxyl for 96 and $48 \mathrm{hrs}$ respectively at the time when the hyphaema was observed but the haemorrhages were immediately preceded by abnormal physical exertion which may have caused them. Patient B1 jumped out of bed to help a fellow patient in distress and Patient B5 had a nightmare. The remaining three patients (A4, B4, A6) were either not receiving Adrenoxyl when the hyphaema developed or the condition was discovered in the course of the first day of Adrenoxyl therapy, and could therefore have developed at any time after the previous daily dressing, before or after the resumption of Adrenoxyl.

No correlation was found between the development of hyphaema and capillary resistance, even when the figures relating to the day when the hyphaema was observed were compared with those of adjacent days or with the mean.

\section{Part II. Effect of Adrenoxyl on Incidence of Post-operative HYPHAEMA}

Because of the results outlined above, the trial was continued in a modified form to see whether Adrenoxyl would prevent or reduce the incidence of delayed hyphaema. The methods used were similar to those in the preceding section, but were restricted to clinical observation. Adrenoxyl was given by mouth throughout the stay in hospital of alternate patients undergoing lens extraction. Consecutive patients admitted for lens extraction were paired so long as they were of the same sex and had in common the presence or absence of diabetes mellitus. By random choice one of each pair was given Adrenoxyl $10 \mathrm{mg}$. (4 tabs) by mouth 8-hrly for the duration of his stay in hospital. The other was not given Adrenoxyl, but was observed clinically with the same care. Forty patients were treated thus with Adrenoxyl and forty had none. The lens extractions were carried out under similar conditions in all cases.

Of the forty patients receiving Adrenoxyl, eight developed hyphaema between the first and 11 th post-operative days (Table III, opposite). There is, however, an increased incidence of cardiorenal vascular disease in diabetes mellitus, and in diastolic hypertension. In both these conditions abnormal capillaries are more likely to be present than in non-diabetics and nonhypertensives (Brown and Roth, 1927). If, therefore, one excludes hyphaemas occurring in patients with a diastolic blood pressure of more than $100 \mathrm{~mm}$. $\mathrm{Hg}$ and in patients with diabetes mellitus, then six patients receiving Adrenoxyl developed post-operative hyphaema as opposed to seven not receiving Adrenoxyl. One of these seven patients already had old synechiae from previous iritis.

No toxic effects of Adrenoxyl were found. 
TABLE III

DETAILS OF PATIENTS DEVELOPING HYPHAEMA

\begin{tabular}{|c|c|c|c|c|c|c|}
\hline $\begin{array}{l}\text { Case } \\
\text { No. }\end{array}$ & Sex & $\begin{array}{l}\text { Age } \\
\text { (yrs) }\end{array}$ & Adrenoxyl & $\begin{array}{c}\text { Post-operative Day of } \\
\text { Onset or Recurrence of } \\
\text { Hyphaema }\end{array}$ & Diabetes & $\begin{array}{c}\text { Blood Pressure } \\
(\mathrm{mm} . \mathrm{Hg})\end{array}$ \\
\hline $\begin{array}{r}1 \\
9 \\
15 \\
19 \\
23 \\
29 \\
57 \\
67 \\
4 \\
6 \\
16 \\
28 \\
32 \\
38 \\
41 \\
62 \\
66 \\
70 \\
80\end{array}$ & $\begin{array}{l}\mathbf{F} \\
\mathbf{M} \\
\mathbf{M} \\
\mathbf{M} \\
\mathbf{F} \\
\mathbf{F} \\
\mathbf{F} \\
\mathbf{M} \\
\mathbf{M} \\
\mathbf{F} \\
\mathbf{M} \\
\mathbf{F} \\
\mathbf{F} \\
\mathbf{M} \\
\mathbf{M} \\
\mathbf{M} \\
\mathbf{F} \\
\mathbf{F} \\
\mathbf{F}\end{array}$ & $\begin{array}{l}79 \\
54 \\
68 \\
48 \\
44 \\
70 \\
76 \\
72 \\
75 \\
67 \\
79 \\
69 \\
61 \\
82 \\
69 \\
47 \\
53 \\
59 \\
65\end{array}$ & $\begin{array}{l}+ \\
+ \\
+ \\
+ \\
+ \\
+ \\
+ \\
+ \\
- \\
- \\
- \\
- \\
- \\
- \\
- \\
- \\
- \\
-\end{array}$ & $\begin{array}{c}10 \\
6 \\
5,9 \\
1 \\
3,10 \\
1 \\
8 \\
1 \\
2 \\
2 \\
7,9 \\
1 \\
2,7 \\
1 \\
10 \\
1,11 \\
1^{*} \\
3 \\
5\end{array}$ & $\begin{array}{l}- \\
- \\
- \\
- \\
= \\
- \\
+ \\
- \\
= \\
- \\
+ \\
- \\
- \\
= \\
+ \\
+\end{array}$ & $\begin{array}{l}280 / 120 \\
130 / 82 \\
140 / 80 \\
140 / 80 \\
140 / 80 \\
150 / 80 \\
138 / 60 \\
220 /- \\
160 / 100 \\
250 / 130 \\
135 / 85 \\
145 / 85 \\
160 / 90 \\
150 / 90 \\
220 / 110 \\
118 / 100 \\
150 / 90 \\
150 /-- \\
137 / 70\end{array}$ \\
\hline
\end{tabular}

* Iritis in 1952

\section{Discussion}

Adrenoxyl, a relatively expensive drug, has been used widely on the continent of Europe for the prevention and treatment of haemorrhage, often with apparently satisfactory results, but there is a paucity of reports in the literature of the English-speaking countries. We find much of the published work difficult to evaluate. Thus, for example, Roskam (1954) gives calcium chloride and thrombase in addition to Adrenoxyl as preventive measures. So far as ophthalmic surgery is concerned, Böhringer (1952) gave Adrenoxyl orally and parenterally to prevent hyphaema after cataract operations. He found delayed hyphaemas after 21.6 per cent. of 185 cataract operations on elderly patients not treated with Adrenoxyl, and after $12 \cdot 1$ per cent. of 63 operations on patients treated with Adrenoxyl. So far as other forms of cataract were concerned, delayed hyphaema occurred in 15.7 per cent. of 77 untreated patients, compared with 12.8 per cent. of 47 patients treated with Adrenoxyl.

In the first part of the present series where 4 days of Adrenoxyl therapy alternated with 4 days without Adrenoxyl for each patient, it appears that the Adrenoxyl as given had no significant effect on capillary resistance; nor did it prevent the development of delayed hyphaema unassociated with abnormal exercise in at least one case.

It is of interest to note that, although capillary resistance commonly tended to rise after operation in our series, it occasionally fell quite markedly; but 
a fall in capillary resistance was not necessarily associated with hyphaema, and hyphaema also occurred in patients in whom there was no apparent lessening of capillary strength.

\section{SUMMARY}

Sixteen patients undergoing lens extraction for cataract were given Adrenoxyl in a dosage of four tablets $(10 \mathrm{mg}$.) by mouth 8-hrly in a controlled trial of the drug.

Adrenoxyl thus given had no statistically significant effect on capillary resistance as measured by a negative pressure method. No apparent relationship was seen between the development of delayed hyphaema and changes in capillary resistance.

There was no apparent difference in the incidence of post-operative hyphaema in a series of forty pairs of patients, one of each pair receiving Adrenoxyl by mouth, and the other being treated similarly in all respects except for the administration of Adrenoxyl.

We thank Miss P. A. Hall, B.Sc., for technical assistance and Dr. J. L. Potter for advice on the construction of the resistometer apparatus. We are indebted to Sister M. Brown and her staff for their excellent cooperation in the trials. One of us (E. K. B.) is grateful to the Endowment Fund of the Board of Governors of the United Sheffield Hospitals for a research grant.

\section{REFERENCES}

Biggs, R., Macfarlane, R. G., and Pilling, J. (1947). Lancet, 1, 402.

BöHRINGER, H. R. (1952). Schweiz. med. Wschr., 82, 484.

Braconier, F., Le Bihan, H., and Beaudet, C. (1943). Arch. int. Pharmacodyn., 69, 181.

Brown, G. E., and Roth, G. M. (1927). Med. J. Aust., 1, 499.

Cauwenberge, H. van, Lecomte, J., Fischer, P., Vliers, M., and Goblet, J. (1953). Arch. int. Pharmacodyn, 93, 317.

GREEN, D. E., and RICHTER, D. (1937). Biochem. J., 31, 596.

HERvÉ, A. (1951). Arch. int. Pharmacodyn, 85, 242.

Prévost, H., Cotereau, H., and Parrot, J.-L. (1947). C. R. Soc. Biol., 141, 1043.

RoBSon, H. N., and DUTHIE, J. R. (1950). Brit. med. J., $2,971$.

Roskam, J. (1954). "Arrest of Bleeding. Physiology, Pharmacology, Pathology", p. 53. Thomas, Springfield, Ill.

and DEROUAUX, G. (1944). Arch. int. Pharmacodyn., 69, 348.

SCARBOROUGH, H. (1941). Edinb. med. J., 48, 555. 